\title{
Correction to: Design, fabrication, and characterization of thermal and optical properties of nano-composite self-cleaning smart window
}

\author{
Mehdi Jafari Vardanjani $^{1} \cdot$ Mehdi Karevan $^{2} \cdot$ Mohsen Safavi $^{2}$
}

Published online: 21 November 2021

(c) Springer Science+Business Media, LLC, part of Springer Nature 2021

\section{Correction to: Optical and Quantum Electronics (2021) 53:600 https://doi.org/10.1007/s11082-021-03250-x}

In the original publication of the article, the third author name Mohsen Safavi was not included. This has been now corrected with this Correction.

Publisher's Note Springer Nature remains neutral with regard to jurisdictional claims in published maps and institutional affiliations.

The original article can be found online at https://doi.org/10.1007/s11082-021-03250-x.

Mehdi Jafari Vardanjani

m-jafari@tvu.ac.ir

1 Department of Mechanical Engineering, Technical and Vocational University (TVU), Tehran, Iran

2 Department of Mechanical Engineering, Isfahan University of Technology, Isfahan, Iran 